\title{
Um antropólogo no gabinete: Notas sobre etnografia e o trabalho no parlamento
}

\author{
GuSTAVO BELISÁRIO D’ARAÚJO COUTO iD \\ Universidade Estadual de Campinas | Campinas, SP, Brasil \\ pp.belisario@gmail.com
}

DOI 10.11606/issn.2316-9133.v30i1pe185626

\begin{abstract}
resumo Este artigo discute como se dá o cotidiano do trabalho de um antropólogo no parlamento. A partir de reflexões de tom etnográfico de experiências do trabalho na equipe técnica do Deputado Distrital Fábio Félix (PSOL - DF) na Câmara Legislativa do Distrito Federal, discuto o impacto da trajetória de formação em antropologia na feitura de documentos legislativos e na maneira de encarar o jogo político. As distintas maneiras de conceber relevância política, valorar os temas e contar histórias são discrepâncias que produzem estranhamentos no antropólogo que atuam no parlamento. Em síntese, no que pese as diferenças entre fazer etnografias e produzir leis, encarar o parlamento sem levar tão a sério a brincadeira é uma conciliação possível para seguir fazendo as duas coisas.
\end{abstract}

palavras-chave Parlamento. Etnografia. Política. Brincadeira. parliament

An anthropologist in the office: on ethnography and the work in the

abstract This article discusses the daily work of an anthropologist in parliament. Based on reflections with an ethnographic style on the work experiences in the technical team of District Deputy Fábio Félix in the Legislative Chamber of the Federal District, it discusses the impact of the academic path in anthropology in the production of legislative documents and in the way of facing the political game. The different ways of conceiving political relevance, valuing themes, and telling stories are discrepancies that produce strangeness in the anthropologist who works in parliament. In summary, despite the differences between making ethnographies and producing laws, facing parliament without taking it so seriously is a possible compromise to keep doing both.

keywords Parliament. Ethnography. Politics. Play. 


\section{Parlamento \\ Un antropólogo en el despacho: apuntes sobre etnografía y el trabajo en el}

resumen El artículo analiza el trabajo diario de un antropólogo en el Parlamento. Basado en las reflexiones etnográficas de las experiencias de trabajo en el equipo técnico del diputado Fábio Félix en la Cámara Legislativa del Distrito Federal, discuto el impacto de la trayectoria de formación en antropología en la elaboración de los documentos legislativos y la forma de enfrentar el juego político. Las distintas formas de concebir la relevancia política, de valorar los temas y de contar las historias son discrepancias que producen extrañeza en los antropólogos que trabajan en el parlamento. Por ello, a pesar de las diferencias entre hacer etnografías y elaborar leyes, enfrentarse al parlamento sin tomarse el juego tan en serio es una posible conciliación para seguir haciendo ambas cosas.

palabras clave Parlamento. Etnografía. Política. Juego.

\section{Introdução}

Ainda eram poucas pessoas no Espaço Semente - Marielle Vive quando começaram a sair os primeiros resultados das pesquisas boca de urna naquele 9 de outubro de 2018. Os resultados favoráveis a figuras da direita, até então com baixa projeção, como Wilson Witzel (PSC) no Rio de Janeiro ou Ibaneis Rocha (MDB) no Distrito Federal já antecipavam que a tão esperada vitória daquela noite seria acompanhada de um gosto amargo. O Espaço Semente foi um polo dinamizador de algumas das campanhas de candidatos proporcionais do Partido Socialismo e Liberdade (PSOL) nas eleições daquele ano. Na ocasião, eu coordenava uma das campanhas a Deputado Distrital do partido, a do candidato Raphael Sebba. O partido tinha como expectativa eleger seu primeiro deputado distrital ${ }^{1}$ naquela noite.

Conforme o espaço ficava mais cheio, os resultados das urnas chegavam. Sebba obteve pouco mais de 4 mil votos, ligeiramente abaixo das expectativas que havíamos estipulado. Outros candidatos chegavam com resultados animadores: Talita Victor ${ }^{2}$ chegou a 12 mil votos em sua candidatura a deputada federal e até o anoitecer já tínhamos o resultado de que, com mais de 10 mil votos, Fábio Félix tinha sido eleito o primeiro deputado distrital pela legenda do PSOL. A alegria do feito logo foi tomada por sentimentos de angústia e medo pelos mais de 49 milhões de votos que levaram Jair Bolsonaro (na época do PSL) com favoritismo para o segundo turno. Em vez de uma comemoração, rapidamente o espaço se tornou uma plenária com falas angustiadas anunciando a resistência a tempos duros.

\footnotetext{
${ }^{1}$ No Distrito Federal, por ser uma unidade da federação que acumula funções administrativas de estado e de município, o parlamento local é representado pelos Deputados Distritais, que possuem atribuições comuns a vereadores e a deputados estaduais nas outras unidades da federação

${ }^{2}$ Talita Victor pertence a mesma organização política que eu, a Insurgência
} 
A partir desse dia, começaram as tratativas internas para a composição do mandato. Em uma composição com setores do partido, acabei sendo chamado para trabalhar no gabinete como assessor, entrando na equipe Jurídica Legislativa (Juslegis), responsável pela produção legislativa do mandato. A composição dos mandatos costuma obedecer a critérios políticos, de forma que os setores do partido que tem mais afinidade e proximidade estratégica tendem a ser convidados nesse esforço de arranjo. Para essas vagas, os aspectos técnicos são relevantes, mas a porta de entrada é política.

Inicio esse artigo com essa anedota do dia da eleição para ilustrar três questões que considero fundamentais em se tratando de um dossiê sobre antropologia e mercado de trabalho. Em primeiro lugar, essa experiência sobre o ofício de um antropólogo em um mandato parlamentar que narro nas próximas páginas é atravessada por um contexto. Como não poderia deixar de ser, não há um trabalho em um mandato parlamentar no abstrato, mas sim posições, documentos, escritas que são construídas em conjunturas particulares. A experiência que está relatada abaixo está atravessada pela eleição de governos que aplicam políticas de extrema direita a nível distrital e nacional.

Em segundo lugar, acredito que com essa passagem fica explícito que a composição do mandato se deu por um arranjo de setores do PSOL. Não houve abertura para uma vaga de "antropólogo" no gabinete, ressalva que acredito ser fundamental para entender o papel da Antropologia no mercado de trabalho. A despeito da minha trajetória e formação em antropologia informarem a ação política que desenvolvo, o convite para trabalhar no mandato teve mais relação direta com a atuação político partidária do que necessariamente por essa trajetória de formação. No entanto, como pretendo demonstrar ao longo do artigo, a trajetória e a formação em Antropologia ao longo do mestrado e do doutorado inevitavelmente impactaram no cotidiano do trabalho que desenvolvi e desenvolvo no âmbito do parlamento.

A terceira razão por colocar esse trecho é para mostrar que mesmo quando se está trabalhando, militando, vivendo, o fazer etnográfico não cessa. Como Mariza Peirano (2014) aponta em Etnografia não é método, a etnografia não é algo que se liga ou desliga. A autora narra uma ida a um posto eleitoral e que a suscitou para essa essência do fazer etnográfico de estranhar situações corriqueiras:

A ideia de "método etnográfico" é complexa. O que eu estava fazendo no posto eleitoral? Simplesmente me recadastrando...? Ou fazendo etnografia? Ou as duas coisas? Desse episódio fica claro que a pesquisa de campo não tem momento certo para começar e acabar. Esses momentos são arbitrários por definição e dependem, hoje que abandonamos as grandes travessias para ilhas isoladas e exóticas, da potencialidade de estranhamento, do insólito da experiência, da necessidade de examinar porque alguns eventos, vividos ou 
observados, nos surpreendem. E é assim que nos tornamos agentes na etnografia, não apenas como investigadores, mas nativos/etnógrafos (Peirano, 2014: 379)

Assim, como Peirano, eu poderia me perguntar: o que eu estava fazendo na Câmara Legislativa do Distrito Federal? Trabalhando ou fazendo etnografia? Ao longo deste artigo, trarei cenas, como a narrada acima, em que eu não necessariamente estava buscando fazer etnografia no trabalho, mas que me despertaram para estranhamentos que podem ser tidos por etnográficos.

\section{Produção legislativa e a etnografia}

Um dos estranhamentos do antropólogo que trabalha no parlamento é o cotidiano da escrita dos documentos legislativos. O exercício parlamentar envolve a escrita de alguns tipos de documentos, no caso da CLDF fixados no Regimento Interno da Câmara Legislativa do Distrito Federal. Os mais comuns são: Projetos de Lei, Requerimentos de Informação, Indicações e Moções. Os Projetos de Lei, em todas as suas variações (Projetos de Lei Complementar, Projeto de Emenda à Lei Orgânica etc.), são os instrumentos intrínsecos à atividade parlamentar. A escrita, análise e aprovação deles em comissões e plenários é o que tece as leis (no caso, distritais) e constitui a maior força formal dos parlamentares. Os Requerimentos de Informação e as Indicações são direcionadas ao Poder Executivo, que tem a capacidade prevista de responder as perguntas feitas e de acatar ou não as sugestões dadas pelos parlamentares. Por fim, as moções têm peso simbólico e, em geral, são destinadas a homenagear pessoas que os parlamentares considerem destacadas da sociedade. Parte da rotina de trabalho na Equipe Jurídica Legislativa do gabinete envolve escrever esses documentos, analisar a produção legislativa dos outros parlamentares e do Governo do Distrito Federal e articular aprovações e derrubadas no Plenário e nas Comissões.

Tanto antropólogos quanto as equipes que produzem os documentos legislativos nos parlamentos têm que escrever bastante em seus ofícios. Entretanto, a forma de escrever esses documentos legislativos e as etnografias tendem a ser muito distintas, a começar pela predileção no parlamento pelas grandes narrativas. Diferente das etnografias (ou ao menos daquelas etnografias mais interessantes), a narrativa produzida nos parlamentos tem uma tendência de fugir do imprevisível, ignorar o detalhe, desvalorizar o específico e não estranhar o ordinário. A produção legislativa pretende produzir leis que valham para todos, universalmente, em todo o território da jurisdição daquele parlamento. Aquilo que é efêmero, passageiro, particular e contextual tende a ter menos relevância na produção das leis.

Por outro lado, a boa etnografia, como nos lembra Mariza Peirano (1995), não é necessariamente aquela que tem pressa em chegar nas formulações gerais e universais. O que 
caracteriza a etnografia, e a antropologia como disciplina que busca produzir boas etnografias, é de colocar a prova a universalidade à dinâmica da vida humana, tendo especial atenção às particularidades de cada contexto:

Notoriamente preocupada com a peculiaridade do objeto de pesquisa, a antropologia talvez seja, entre as ciências sociais, paradoxalmente, a mais artesanal e a mais ambiciosa: ao submeter conceitos preestabelecidos à experiência de contextos diferentes e particulares, ela procura dissecar e examinar, para então analisar, a adequação de tais conceitos. [...\} Seu objetivo mais geral, contudo, foi sempre a procura de uma visão alternativa, mais genuína talvez, da universalidade dos conceitos sociológicos. Portanto, não são grandes teorias nem abrangentes arcabouços teóricos que a informam (embora o estruturalismo tenha sido a teoria social deste século), mas, ao contrastar os nossos conceitos com outros conceitos nativos, ela se propõe formular uma ideia de humanidade construída pelas diferenças. (Peirano, 1995:16)

Existe, portanto, uma forma de produzir narrativas muito distintas entre as etnografias e os parlamentos, o que torna o trabalho de um antropólogo no parlamento, por vezes, contraditório. A velocidade em que se produzem projetos com pretensões universalistas de se tornarem Lei nem sempre é compatível com essa atenção ao detalhe, com a dinâmica da vida cotidiana. E, por isso, as grandes narrativas do parlamento priorizam lugares comuns como o crescimento econômico, o empreendedorismo, a orçamento, a violência etc. Nessa narrativa avessa aos estranhamentos do ordinário e aos olhares atentos a dinâmica da vida cotidiana, escapam dos temas prioritários da produção legislativa a epifania sobre o recadastramento biométrico, as brincadeiras das crianças, a menstruação, o contador de histórias e outros temas caros aos etnógrafos.

$\mathrm{O}$ antropólogo que trabalha no parlamento, na sua rejeição às grandes narrativas, acaba pegando para si temas diversos, heterodoxos ou, até mesmo, aleatórios. Enquanto os demais integrantes das equipes se debruçam sobre os grandes temas, o antropólogo atrai para si as análises de projetos sobre regularização fundiária, defesa do direito a água, resíduos sólidos, regulamentação de antenas parabólicas, direitos das crianças e adolescentes, combate ao feminicídio. São aqueles temas que mais escapam da predileção do parlamento justamente os que o antropólogo mais se interessa. Para exemplificar essa disparidade de interesses, trago o relato abaixo sobre a produção de um projeto de lei sobre distribuição de absorventes para mulheres em situação de rua. 
Estávamos na sala de reuniões com a Equipe Jurídico Legislativa para apreciar as demandas da semana. Depois de despachar algumas pautas orçamentárias para o orçamentista e a feitura de um PL sobre regulamentação e controle de armas de fogo no Distrito Federal, o Coordenador disse que uma das apoiadoras do mandato havia sugerido por meio das redes sociais que fosse apresentado um Projeto de Lei para a distribuição de absorventes para pessoas em situação de rua. Olhei ao redor da mesa e, aparentemente, nenhum dos colegas juristas e cientistas políticos pareceu interessado em escrever tal projeto. Em meio ao silêncio, apresentei imediato interesse que apresentei para que fosse o responsável pela escrita daquele projeto. Vendo a expressão do meu interesse, o Coordenador delegou que eu fizesse a primeira minuta.

A menstruação enquanto um tabu, por sua associação simbólica à impureza do sangue menstrual, acaba por vedar a discussão pública do tema e, talvez por essa razão, não ser levada em consideração nas grandes narrativas da política. A mesma raiz que constrange o debate público sobre menstruação é a que produz situações de risco para as mulheres sem condições econômicas para comprarem os absorventes higiênicos. No caso de vários relatos de mulheres em situação de rua ou de presidiárias, estão presentes o uso de meias, plásticos, miolo de pão, jornal e peças de roupa para conter os fluxos menstruais. A despeito da pouca relevância que as grandes narrativas da política dão a menstruação, a escrita do Projeto de Lei 449/2019 sobre a distribuição de absorventes foi uma das experiências de maior aprendizado ao longo do trabalho no mandato. ${ }^{3}$

Enquanto na vida cotidiana e nas etnografias alguns temas tidos como tabus tem implicações profundas, os documentos legislativos tendem a tê-los como menos interessantes ou irrelevantes para a política. No entanto, o que seria a construção de um projeto de lei de pouca relevância na narrativa tradicional se tornou um processo rico de pensar a política a partir de outros prismas.

\section{Escrita legislativa: Contando histórias}

O abismo entre as formas de escrita dos projetos de lei e das etnografias não é suficientemente largo ao ponto de vedar totalmente as brechas para que contemos boas histórias através dos documentos legislativos. Mesmo nos projetos de lei mais sisudos, há alguma liberdade para poder comunicar uma mensagem que vá além da simples descrição da relevância ou efeitos dos projetos de lei. E é nessas brechas que o antropólogo pode contar histórias, podendo imaginar-se, por alguns instantes, fazendo etnografia.

Os Projetos de Lei costumam se dividir em duas partes: a parte da lei propriamente dita (com seus artigos e dispositivos legais) e a parte da "justificação", que é um texto corrido que dá

\footnotetext{
${ }^{3}$ O projeto de lei prevê a obrigatoriedade do Governo do Distrito Federal fornecer absorventes higiênicos de forma gratuita a serem retirados nos Centros de Referência Especializada para a População em Situação de Rua (CENTRO POP) pelas pessoas em situação de rua que demandarem.
} 
argumento político para a relevância e necessidade de aprovação daquele projeto. Diferente da parte que contém os dispositivos, a parte da "justificação" guarda uma miríade de possibilidades de escrita, com mais liberdade para usar a linguagem que não se limita a uma linguagem referencial. É na parte da "justificação" que é mais fácil colorir os projetos com um pouco de dinâmica vivida e com a magia da etnografia. Entretanto, a parte da "justificação" dos Projetos de Lei costumam ser recheados de estatísticas e de referência a outras leis. Justifica-se a necessidade da aprovação da lei por ela ser coerente com o arcabouço jurídico (constituída por leis de distintas hierarquias como a Constituição, Projetos de Lei Complementares, Projetos de Lei, Decretos etc.) e por ela descrever os fatos de maneira fidedigna com a verdade por meio das estatísticas.

O sentido e o impacto do projeto na vida das pessoas, em como serão contadas as histórias das pessoas, recorrentemente fica em segundo plano na escrita dos projetos de lei. A ação vivida e a experiência tendem a ter um peso menor na argumentação para a aprovação daquela lei. Essa maneira de escrever é bem distinta do que Mariza Peirano chama de boa etnografia:

A primeira e mais importante qualidade de uma boa etnografia reside, então, em ultrapassar o senso comum quanto aos usos da linguagem. Se o trabalho de campo se faz pelo diálogo vivido que, depois, é revelado por meio da escrita, é necessário ultrapassar o senso comum ocidental que acredita que a linguagem é basicamente referencial. Que ela apenas "diz" e "descreve”, com base na relação entre uma palavra e uma coisa. Ao contrário, palavras fazem coisas, trazem consequências, realizam tarefas, comunicam e produzem resultados. E palavras não são o único meio de comunicação: silêncios comunicam. Da mesma maneira, os outros sentidos (olfato, visão, espaço, tato) têm implicações que é necessário avaliar e analisar. Dito de outra forma, é preciso colocar no texto - em palavras sequenciais, em frases que se seguem umas às outras, em parágrafos e capítulos - o que foi ação vivida. Este talvez seja um dos maiores desafios da etnografia - e não há receitas preestabelecidas de como fazê-lo. (Peirano, 2014: 379)

O antropólogo que trabalha no parlamento fazendo documentos legislativos encontra na escrita da "justificação" as brechas para contar histórias. O primeiro Projeto de Lei que escrevi, o 354/2019, trouxe em sua "justificação" uma tentativa de contaminar esse aspecto universalista da Lei com um pouco da história e vida de Kyara, mulher transexual que foi expulsa de casa pelo pai. O PL prevê que pessoas LGBT expulsas de casa entrem nos critérios de priorização da política habitacional do Distrito Federal e parte de reflexões que desenvolvo no 
Doutorado. ${ }^{4}$ Assim, o trecho a seguir, que abre a "justificação" do PL 354/2019, é parte da busca da mediação entre essas reflexões etnográficas e o texto legislativo:

"Kyara Zaruty da Salva foi expulsa da casa da família aos 16 anos. Desde os 13 anos tinha uma convivência conflituosa com seus pais por, na época, ter revelado a eles que era gay. Com o passar do tempo, ao notar que era uma mulher transexual, seu pai disse para ela: "Eu não aceito você dessa forma. Ou você vive dentro da minha casa como homem ou vai viver na rua como mulher". Kyara demorou anos para reconstruir sua vida, tendo passado por casas de amigos, diferentes empregos e dificuldades.

A história de Kyara é a mesma de inúmeras lésbicas, gays, bissexuais e transexuais pelo país, que, por intolerância e preconceito de suas famílias, são expulsas de casa especificamente em razão de sua orientação sexual e/ou identidade de gênero. $\mathrm{O}$ abandono gera redução drástica de renda familiar, resultando em contexto de vulnerabilidade nos termos do Artigo 2', inciso 1, da Resolução n' 266/2018 da Companhia de Desenvolvimento Habitacional do Distrito Federal (CODHAB).” (BRASIL. Câmara Legislativa do Distrito Federal. Projeto de lei 354/2019).

Essa tentativa tímida de trazer um ar de etnografia para a "justificação" do Projeto de Lei foi entendida como heterodoxa. Uma colega jurista falou da originalidade de "escrever histórias" na "justificação" de um projeto. Vistas como muito pessoais e particulares, essas histórias produzem um estranhamento entre os assessores do parlamento acostumados a discutir a universalidade das Leis. Apesar de não ser comum, acredito que o contar histórias carrega a força da reflexão sobre os impactos das leis nas vidas das pessoas e pode, em certos casos, produzir efeitos imprevisíveis.

Situação similar aconteceu enquanto escrevíamos o relatório da CPI do feminicídio. $\mathrm{Na}$ reunião voltada a pensar o sumário do relatório, entre análises de documentos e estatísticas, a estrutura pensada inicialmente para o texto não tinha previsão de contar histórias das pessoas. Sugeri que tratássemos, com a delicadeza necessária, essas histórias em uma seção destinada aos “casos emblemáticos”, que foi incorporada.

\footnotetext{
${ }^{4}$ Busco, em minha tese, fazer uma etnografia que pense a relação entre casa, gênero e sexualidade a partir de diálogos com pessoas LGBT que frequentaram ocupações de movimentos de moradia.
} 
O antropólogo no parlamento é instigado a contar outras histórias de outras maneiras que não se reduzam a simples descrição dos fatos. Frente a quantidade de textos que precisa produzir, há sempre uma brecha para que a magia da etnografia possa acenar.

\section{Política como brincadeira}

Quando levamos a sério demais, há uma contradição insolúvel entre fazer etnografia e trabalhar no parlamento, angústia crescente quando o sentido original de fazer etnografia e de fazer política se perde em meio às rotinas, prazos, entregas e análises cotidianas. Contar histórias, na minúcia e sensibilidade que exige a etnografia, requer um tempo que nem sempre é possível frente a quantidade de demandas e prazos. Quando menos se percebe, os textos passam a sair cheios de estatísticas e sem aquele envolvimento visceral que a trajetória adverte ser a melhor etnografia. As reuniões viram rotina. Os formulários viram hábito. Os processos do Estado transformam-se em cotidiano.

Ver-me cedendo a seriedade dos processos do Estado reacendeu a necessidade de revisitar a dissertação de mestrado e, particularmente, as comparações entre brincadeira e política, brincadeira e antropologia (Belisario, 2016). Recuperar a discussão junto a Walter Benjamin (2009) sobre a persistência das brincadeiras e da ludicidade, mesmo nas tarefas mais burocráticas, facilita na hora de levar menos a sério o parlamento e o próprio ofício do etnógrafo:

O hábito entra na vida como brincadeira, e nele, mesmo em suas formas mais enrijecidas, sobrevive até o final um restinho de brincadeira. Formas petrificadas e irreconhecíveis de nossa primeira felicidade, de nosso primeiro terror, eis o que são os hábitos. E mesmo o pedante mais insípido brinca, sem o saber, de maneira pueril, não infantil, brinca ao máximo quando é pedante ao máximo. Acontece apenas que ele não se lembrará de suas brincadeiras, somente para ele uma obra como essa permaneceria muda. (Benjamin, 2009: 102)

A constatação de que brincadeira e as atividades do Estado tinham alguma semelhança surgiu do acompanhamento das reuniões que o MST fez com o INCRA enquanto eu voltava a minha atenção às crianças do acampamento e suas brincadeiras. De tantas idas e vindas que o processo de regularização fundiária da terra ocupada pelo movimento teve, os acampados começaram a dizer que os servidores do INCRA "estavam de brincadeira”. E quanto mais os servidores do INCRA reafirmavam que "não estavam brincando", mais reafirmavam a rigidez das regras e técnicas que adiavam o encontro dos acampados com os documentos que aferiam que a terra era deles. Isso produziu o questionamento: "Se Luiz [servidor fictício do INCRA] 
precisa negar que a reforma agrária é brincadeira, é porque é possível confundi-la com uma. Se oposição entre uma reunião burocrática e uma brincadeira precisam ser o tempo todo evidenciadas é porque devem ter alguma semelhança." (Belisário, 2016: 83) Da investigação sobre as semelhanças entre a brincadeira e a política na relação com o INCRA, a conclusão foi a seguinte:

O INCRA age como quem leva a sério demais a brincadeira ao enfatizar tanto o domínio da lei e das regras. Paralisa todos os processos porque as regras não estão sendo cumpridas. Esquece-se que trata-se de uma brincadeira e, como na esquizofrenia, não reconhece a natureza metafórica de sua fantasia (BATESON, 1972). O interessante é que quanto mais leva a sério suas leis, protocolos e formulários, mais o tempo da brincadeira se alonga. Quanto mais pedante é o INCRA com as regras, mais tempo as famílias passam pela privação, em reuniões repetitivas. A flexibilização das regras é inconcebível em favor dos movimentos sociais. (Belisário, 2016: 90)

O ensinamento de que há algo de brincadeira nos processos do Estado e que, portanto, não devem ser levados tão a sério assim tem sido essencial para seguir fazendo etnografia e trabalhando no parlamento ao mesmo tempo. A lembrança de que, no fundo, trata-se de uma brincadeira é uma lufada de serenidade em meio a quantidade de rotinas, análises de processos, documentos legislativos a serem escritos e dissipa a indiferença à dor dos outros que o cotidiano da burocracia estatal incorpora (Herzfeld, 1993).

A um olhar mais cansado e viciado da burocracia, pode parecer um contrassenso que encarar os processos como brincadeiras não provoque uma rotina mais insensível às dores das pessoas que estão fora da Câmara Legislativa. Afinal, como afirma Schwartzman (1978), a brincadeira sempre foi entendida no mundo moderno como o oposto do que é considerado sério e produtivo. Ao levar ainda mais a sério as rotinas e os projetos de lei, seria possível garantir, intuitivamente, menos indiferença com quem espera do Estado alguma coisa. Entretanto, a experiência no parlamento me confirma que essas pausas e recuperações do sentido da brincadeira são o que permite a quebra dessa indiferença.

É o caso quando essa lembrança permite parar e fazer um texto com mais cara de etnografia, contando histórias. Mas é o caso também quando o andamento dos processos que se quer ver andando no parlamento é paralisado ou adiado por conta de algum servidor que levou a sério demais a brincadeira. O PL 354/2019 acima descrito, por exemplo, que trata sobre a priorização de pessoas LGBT expulsas de casa na política habitacional, foi apensado ao PL 400/2019, tornando mais lenta a possibilidade de ser pautado em Plenário. No requerimento 
que pediu o apensamento do PL reivindicou o artigo 154 do Regimento Interno da Câmara Legislativa do Distrito Federal, que diz:

Art. 154. A tramitação conjunta ocorrerá quando proposições da mesma espécie tratarem de matéria análoga ou correlata.

$\S 1^{\circ}$ A tramitação conjunta será determinada pela Mesa Diretora, de ofício, ou a requerimento de qualquer Deputado Distrital ou comissão.

$\S 2$ Não será deferido o requerimento de tramitação conjunta se todas as comissões de mérito já houverem proferido os seus pareceres. (Brasil. Câmara Legislativa do Distrito Federal. Regimento Interno da Câmara Legislativa do Distrito Federal 2005)

$\mathrm{O}$ uso de um artigo do Regimento Interno aparentemente dá um ar de seriedade a decisão. No entanto, sabe-se que as decisões de apensamento ou não de um projeto de lei a outro não são tão lineares assim como o regimento dá a entender. Há projetos análogos que nunca são apensados e outros que nem são tão análogos assim que acabam apensados. Há inclusive Projetos de Lei que são protocolizados em um dia e pautados em Plenário no outro, sem passar nas Comissões ou sem uma análise regimental tão minuciosa. As trajetórias que os Projetos de Lei perfazem na Câmara Legislativa dependem, em geral, de quem é o autor, de sua proximidade com o Presidente da Câmara ou do Governador, e dos acordos políticos em curso naquele momento.

Nesse contexto, levar a sério demais as regras do jogo pode ser enlouquecedor. Lembrar que se trata de um jogo, de uma brincadeira, da qual se tem pouca participação, ajuda na sobrevivência daqueles que querem levar a sério as etnografias e a dinâmica de vida das pessoas fora do parlamento:

O que chama atenção nessa comparação entre brincadeira e Estado é a oposição que é insistentemente colocada entre as duas coisas. Parece que admitir que o Estado brinca com os prazos invalida qualquer possibilidade de crença nele. Quando os funcionários dizem que "não estão brincando", eles dizem que estão sob o registro do que pede a lei e do que pede o Estado. A brincadeira não pode ser levada tão a sério, enquanto que o Estado só pode ser levado a sério. Pilhas de leis, registros, sistemas e dados são produzidos diariamente por um Estado que não está para brincadeira, e quer saber exatamente como as coisas são. Como óleo e água que não se misturam, a linguagem do Estado não quer ser confundida com uma mera brincadeira. Quanto mais o Estado esforça-se para não ser uma brincadeira e segue suas 
leis e protocolos, mais obstáculos aparecem na vida das pessoas e mais ele assemelha-se a uma. É depois de fazer reuniões, preencher formulários, entrar em filas, imprimir duas vias que o apelo daquela lei que apresenta um novo obstáculo nos faz exclamar: só podem estar de brincadeira comigo. (Belisário, 2016: 93)

No caso do apensamento do PL 354/2019, a apreciação dele em plenário poderia ser muito mais célere, uma vez que os deputados conseguem pautar projetos que não estejam apensados a partir de acordo com os líderes. O projeto foi apreciado e aprovado na primeira comissão apenas dois anos após a protocolização. O tempo de apreciação dos projetos nas comissões e no plenário seguem o ritmo do jogo político, e essa brincadeira de alargar e comprimir prazos, costumeiramente, não é feita de maneira inocente.

\section{Considerações finais}

A incompatibilidade entre as grandes narrativas do jogo político e aquilo que é vivido no dia a dia pelas pessoas está para muito além da presença ou não dos antropólogos nos parlamentos. São muitas páginas destinadas a debater a distância entre representantes e representados da democracia liberal na Ciência Política. Entretanto, a atenção a dinâmica da vida nas suas minúcias e detalhes pode fazer da vida do antropólogo no parlamento, e de seu ofício de fazer boas etnografias, uma tarefa árdua. As discrepâncias podem emergir desde a abordagem e a valoração que se dá às temáticas trabalhadas até a forma de escrever um documento.

Porém, estando presente nesses espaços do jogo político e lembrar as pessoas sobre o valor de contar boas histórias pode ser um ofício substancial. Nadar na contracorrente das grandes narrativas e oferecer aos leitores dos projetos de lei conexões com histórias que são vividas fora do parlamento irrompe, mesmo que naquelas linhas, com a normalização de uma forma de fazer política distante e pouco atenta. Afinal, a avalanche de histórias ruins há de parar em algum momento.

E a persistência de ir na direção contrária das histórias ruins e buscar contar histórias melhores depende do quanto levamos a sério o jogo. Quanto mais nos perdemos nas regras e rotinas do cotidiano do parlamento, menores são as nossas capacidades de persistir contando boas histórias. Lembrar que, ao fim e ao cabo, trata-se de uma brincadeira, é uma estratégia possível para a sobrevivência do antropólogo no parlamento. 


\section{Referências bibliográficas}

BELISÁRIO, Gustavo. 2016. Brincando na terra: tempo, política e faz de conta no acampamento Canaã (MST - DF). 2016. Dissertação de mestrado. Brasília: Universidade de Brasília.

BENJAMIN, Walter. 2009. Reflexões sobre o brinquedo, a criança e a educação. São Paulo: Ed. 34.

BRASIL. 2005. Câmara Legislativa do Distrito Federal. Regimento Interno da Câmara Legislativa do Distrito Federal, estabelecido pela Resolução 218 de 2005. Disponível em: <http://www.sinj.df.gov.br/sinj/Norma/70909/Resolu_o_218_22_07_2005.pdf> acesso em 19-jun-2021

BRASIL. 2019. Câmara Legislativa do Distrito Federal. Projeto de lei 354/2019, que altera a Lei no 3.877 , de 26 de junho de 2006, que dispõe sobre a política habitacional do Distrito Federal. Disponível em <https://legislacao.cl.df.gov.br/Legislacao/consultaProposicao$1 ! 354$ !2019!visualizar.action > acesso em 19-jun-2021

HERZFELD, Michael. 1993. The Social Production of Indifference. Chicago: The University of Chicago Press.

PEIRANO, Mariza. 1995. A favor da etnografia. Rio de Janeiro: Relume-Dumará.

PEIRANO, Mariza. 2014. Etnografia não é método. In: Horizontes Antropológicos, v. 20, n. 42, p. 377-391.

SCHWARTZMAN, Helen. 1978. Transformations: The Anthropology of Children's Play. New York and London: Plenum Press.

sobre o autor

\section{Gustavo Belisário}

É doutorando em Antropologia Social na Universidade Estadual de Campinas (Unicamp) e assessor na Câmara Legislativa do Distrito Federal. Fez mestrado em Antropologia Social na UnB pesquisando infância, brincadeira e política em uma etnografia com crianças do MST.

Contribuição de Autoria: Não se Aplica

Financiamento: A produção deste ensaio não contou com nenhum financiamento.

Recebido em 24/02/2021

Aceito para publicação em 02/06/021 